\title{
Estratégia reprodutiva do peixe voador, Hirundichthys affinis Günther (Osteichthyes, Exocoetidae)
}

\author{
Andréa Soares de Araújo ${ }^{1}$ \\ Sathyabama Chellappa ${ }^{1}$
}

\begin{abstract}
Reproductive strategy of the flying fish, Hirundichthys affinis Gunther (Osteichthyes, Exocoetidae). This study was carried out to investigate the reproductive aspects of the flying fish, Hirundichthys affinis Günther, 1866 considering their importance in the fish production of the Rio Grande do Norte State, Brazil. Fish samples were collected from the Municipality of Caiçara do Norte, northern coast of the state, during the period of April, 1999 to April, 2000. The fish were measured, weighed, dissected and the gonads were examined to separate the sex and to determine the stage of maturation. Histological studies were done for microscopic characterization of the gonads. The results indicated that $H$. affinis had a sexual proportion of $1: 1$; condition factor was inversely related to the gonadosomatic index during the reproductive phase; and the highest for both sexes was registered during the breeding season. Males and females showed four devolopmental stages of the gonads: immature, initial maturation, mature and spent. Absolute fecundity varied from 4400 to 6400 oocytes, with a mean of 5400 . The species presents total spawing and the spawing season occurred in the months of May and June. The rainy season preceeded the occurrence of breeding flying fishes in the coastal waters of Caiçara do Norte.

KEY WORDS. Flying fish, reproductive strategy, gonadal development
\end{abstract}

Estratégia reprodutiva engloba um conjunto de características que determinadas espécies de peixes desenvolvem para serem bem sucedidas na reprodução. Várias táticas reprodutivas modulam uma estratégia reprodutiva (POTTS \& WOOTTON 1984; VAZZOLER 1996). Cada espécie apresenta sua distribuição estabelecida por um conjunto de condições ecológicas, com adaptações anatômicas, fisiológicas, comportamentais e energéticas específicas. Dessa forma, cada espécie deve apresentar uma única estratégia reprodutiva. Porém, quando as condições ambientais variam, determinando mudanças em alguma característica da estratégia, essa variação denomina-se tática reprodutiva, ou seja, característica variável no padrão, em respostas à flutuações do ambiente e portanto a estratégia e a tática são adaptativas (WOOTTON 1984). O sucesso alcançado pelos peixes nos mais distintos ambientes deve-se à enorme quantidade de estratégias reprodutivas desenvolvidas pelo grupo, englobando táticas extremas.

Quando a quantidade de energia é retida na reprodução, as espécies são consideradas r-estrategistas, o que pode ser verificado em ambientes instáveis, onde a melhor estratégia é utilizar o máximo de recursos na reprodução, e produzir o maior número possível de descendentes. Os peixes considerados r-estrategistas

1) Programa de Pós-Graduação em Bioecologia Aquática, Departamento de Oceanografia e Limnologia, Centro de Biociências, Universidade Federal do Rio Grande do Norte. Praia de Mãe Luiza, 59014-100 Natal, Rio Grande do Norte, Brasil. 
apresentam período de desova prolongado, surtos reprodutivos repetidos, distribuição uniforme de tamanhos durante as estações seca e chuvosa, tamanho do corpo e ovócitos pequenos, flutuações populacionais intermediárias e pequeno ou nenhum cuidado parental, por sua vez, as espécies que utilizam os recursos energéticos para o desenvolvimento somático são K-estrategistas, onde a melhor estratégia é despender os recursos para desenvolver a habilidade competitiva, produzindo um menor número de descendentes, porém mais capazes de enfrentar as oscilações do ambiente. Assim, os peixes considerados K-estrategistas são caracterizados por apresentarem cuidado parental bem desenvolvido, período reprodutivo prolongado, desovas parceladas, classes de tamanho distribuídas uniformemente ao longo período de procriação, tamanho do corpo e ovócitos grandes, além de pequenas flutuações populacionais ao longo do ano (WoOTTON et al. 1978).

Os peixes voadores são importantes para a cadeia trófica marinha, sendo uma espécie-forrageira importante na cadeia alimentar de peixes carnívoros, como: atum - Thunnus thynnus (Linnaeus, 1758), tubarão - Carcharhinus sp., agulhão Istiophorus albicans (Latreille, 1804) e dourado-Coryphaena hippurus (Linnaeus, 1758) (PIRES 1997). A carne desses peixes, utilizada atualmente como isca para a pesca de espécies maiores, tem qualidade para ser comercializada como filé e suas ovas são utilizadas para a produção de caviar. Alguns trabalhos sobre a biometria e a fisioecologia foram realizados sobre o peixe voador Hirundichthys affinis Günther, 1866, que ocorre na costa do Rio Grande do Norte (CRUZ 1965; ALMEIDA 1966; MONTE 1965). A sobre-exploração de peixes voadores poderia causar desequilíbrio ecológico, desta forma considerou-se necessário estudar os aspectos reprodutivos de $H$. affinis, tais como: primeira maturação sexual, estádios de desenvolvimento gonadal, fecundidade, tipo de desova, período reprodutivo, índice gonadossomático (IGS) e o fator de condição (K).

\section{MATERIAL E MÉTODOS}

As coletas das amostragens de $H$. affinis foram realizadas no município de Caiçara do Norte, que se destaca no processo de captura desse peixe quando comparado com os demais municípios do Estado do Rio Grande do Norte. Esse município está situado geograficamente no litoral norte do Estado entre as coordenadas $05^{\circ} 03^{\prime} 00^{\prime \prime}$ a $05^{\circ} 05^{\prime} 00^{\prime \prime} \mathrm{S}$ e $36^{\circ} 02^{\prime} 00^{\prime \prime}$ a $36^{\circ} 05^{\prime} 00^{\prime \prime} \mathrm{W}$, distando $156 \mathrm{~km}$ de Natal. Os exemplares foram coletados durante o período de abril de 1999 a abril de 2000 , no total 378 exemplares. As amostras foram levadas em depósitos de isopor com gelo, para o Laboratório de Ictiologia do Departamento de Oceanografia e Limnologia, onde foi confirmada a identificação taxonômica.

Os dados de precipitação pluviométrica da área de estudo foram obtidos no Departamento de Meteorologia e Recursos Hídricos da Empresa de Pesquisa Agropecuária do Rio Grande do Norte S/A (EMPARN), Natal, Rio Grande do Norte.

A determinação da primeira maturação sexual da espécie foi feita pela distribuição da freqüência relativa de machos e fêmeas adultas em classes de comprimento total para o período de estudo. Para a determinação da proporção sexual considerou-se a freqüência relativa de machos e de fêmeas para o período total da amostragem. Foi realizado o teste do $X^{2}$ (Qui-quadrado) com 5\% de significância. 
Para análise dos estádios de maturação gonadal, os exemplares foram seccionados longitudinalmente na superfície ventral até atingir a cavidade celomática. As gônadas foram expostas para observação de suas características morfológicas, como o tamanho em relação à cavidade celomática, coloração, presença de vasos sanguíneos, grau de turgidez das gônadas, tamanho e aspecto dos ovócitos (VAZZOLER 1996).

Após a observação macroscópica, as gônadas foram medidas e pesadas, suas cápsulas foram seccionadas longitudinalmente em toda extensão e colocada em solução de Gilson (modificada segundo SIMPSON 1951). A determinação microscópica dos estádios de maturação das gônadas foi feita segundo VAZZOLER (1996).

Foram realizados estudos histológicos das gônadas dos peixes no Laboratório de Técnicas Histológicas do Departamento de Morfologia, Universidade Federal do Rio Grande do Norte e para tanto, foram tomadas amostras das regiões cranial, mediana e caudal das gônadas em diferentes fases de desenvolvimento; foram fixadas em formol a $4 \%$ neutralizado com carbonato de cálcio ( $\mathrm{CaCO}$ ), e submetidas ao tratamento histológico pelas técnicas de hematoxilina-eosina (HE), segundo a metodologia de MiCHALANY (1990).

A estimativa da fecundidade absoluta foi feita segundo VAZZOLER (1996). O tipo de desova foi avaliado através da análise dos resultados da medição do diâmetro dos ovócitos $(\mathrm{em} \mu \mathrm{m})$ e as freqüências de ocorrência dos ovócitos por classe (em porcentagem). A totalidade de cada classe existente nas subamostras foi contada. Os dados foram lançados em forma de gráficos e interpretados para esclarecer o tipo de desova (WOOTTON et al. 1978).

Com os dados obtidos, como peso do corpo (Wc), comprimento total (Lt), e o peso das gônadas $(\mathrm{Wg})$, foram calculados o fator de condição $(\mathrm{K})$ e o índice gonadossomático (IGS) dos peixes, conforme LE CREN (1951) e WOOTTON (1984).

\section{RESULTADOS}

Os valores de precipitação pluviométrica de Caiçara do Norte, no período de 1995 a 1999, indicam que o clima da região é do tipo semi-árido, com precipitação média anual abaixo de $300 \mathrm{~mm}$. Em geral, a região apresentou um período chuvoso desde o mês de março até maio, e o período de estiagem estendeu-se de setembro a novembro. Durante os cinco anos de 1995 a 1999, a precipitação pluviométrica variou de 0 a $236 \mathrm{~mm}$ (Fig. 1).

Mediante a amostra coletada durante o período de estudo, a distribuição de frequiência de ocorrência de machos e fêmeas de $H$. affinis revelou que a proporção entre os sexos aproximou-se de 1:1, com uma leve predominância de fêmeas nos meses de abril e maio e de machos nos meses de novembro e dezembro (Fig. 2). Para o período total não houve diferença significativa entre a proporção sexual total $\left(X^{2}<3,84\right)$.

O tamanho no qual $50 \%$ dos machos e fêmeas iniciam o processo de maturação gonadal foi de $238 \mathrm{~mm}$ e $230 \mathrm{~mm}$ de comprimento total, respectivamente (Figs 3a, b).

As características macroscópicas e microscópicas dos estádios de maturação gonadal de fêmeas e machos estão, respectivamente, nas tabelas I e II e na figura 4. 


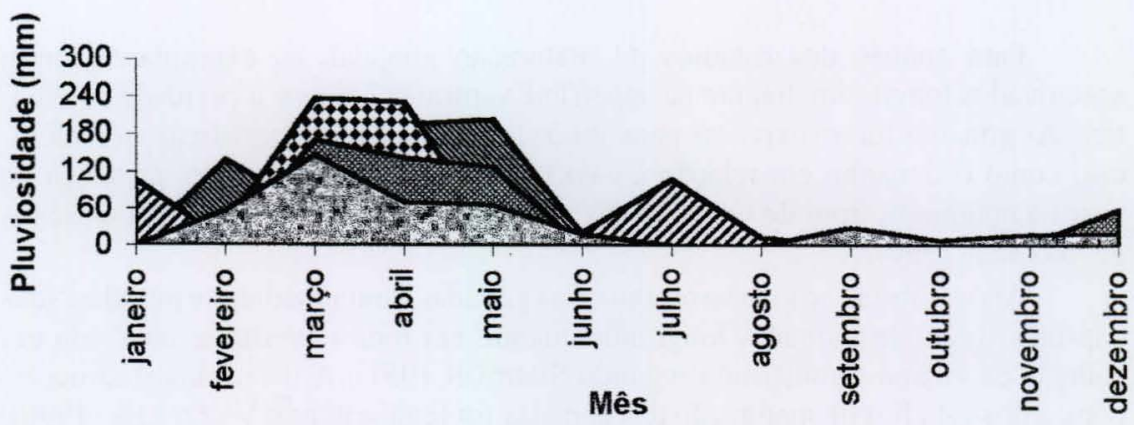

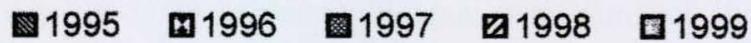

Fig. 1. Dados pluviométricos do Município de Caiçara do Norte durante os anos de 1995 a 1999.

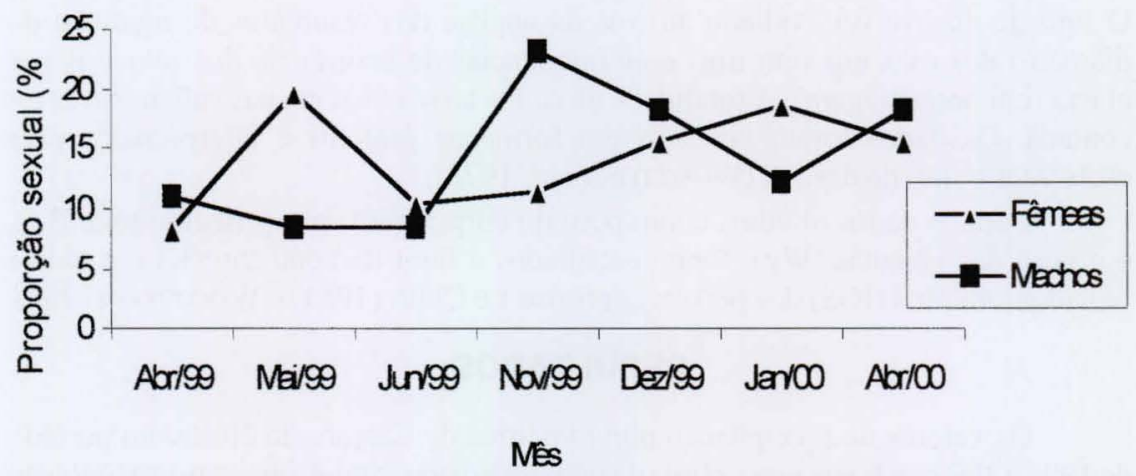

Fig. 2. Proporção sexual mensal de $H$. affinis durante o periodo de estudo.

A fecundidade absoluta do peixe voador variou entre 4.400 e 6.400 ovócitos. Os ovócitos dos peixes em estudo apresentaram forma redonda cujo diâmetros apresentaram amplitude variando de $100 \mu \mathrm{m}$ a $2500 \mu \mathrm{m}$. A figura 5 mostra um desenvolvimento sincrônico em dois grupos: um grupo do estoque de reserva com diâmetros dos ovócitos inferiores a 1000 m, e um grupo de ovócitos em desenvolvimento com diâmetros superiores a $1000 \mu \mathrm{m}$. Baseando-se na média das freqüências de ocorrência dos ovócitos, encontrados em peixes em diversos estádios de maturação gonadal, considerou-se a espécie em estudo apresenta desova do tipo total, eliminando seus ovócitos maduros de uma só vez. Aliado a este resultado, observamos que o desenvolvimento ovocitário dos cortes histológicos também, mostraram nitidamente que não existe num mesmo corte histológico ovócitos em diferentes fases de desenvolvimento, havendo apenas predominância de uma fase ovocitária. 

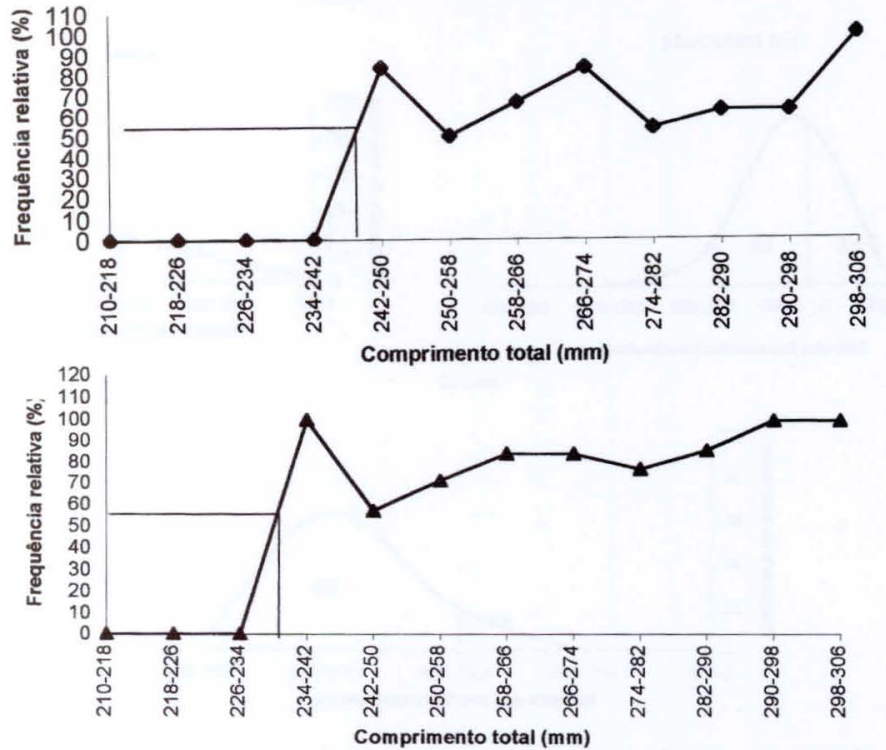

Fig. 3. (a) Curva de maturação para machos de $H$. affinis, mostrando o comprimento média da primeira maturação ( $\left(L_{50}\right)$; (3b) curva de maturação para fêmeas de $H$. affinis, mostrando o comprimento média da primeira maturação ( $\left.L_{50}\right)$.

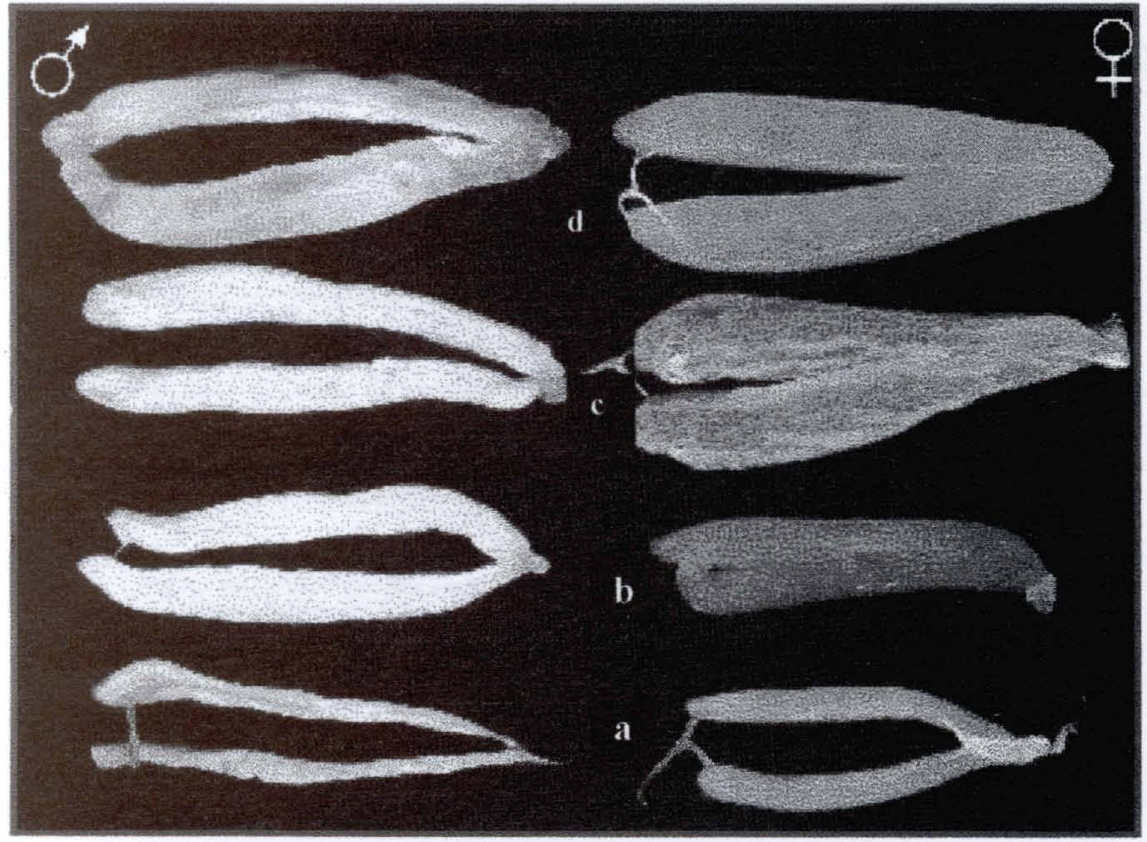

Fig. 4. Gônadas de macho e fêmea nos diversos estádios de maturação: (a) imaturo, (b) em maturação I, (c) em maturação II, (d) maduro. 

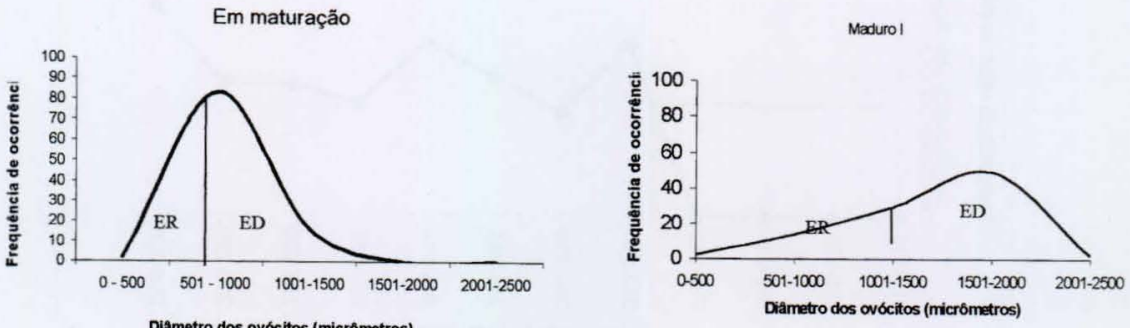

Diametro dos ovócitos (micrómetros)

Maduroll

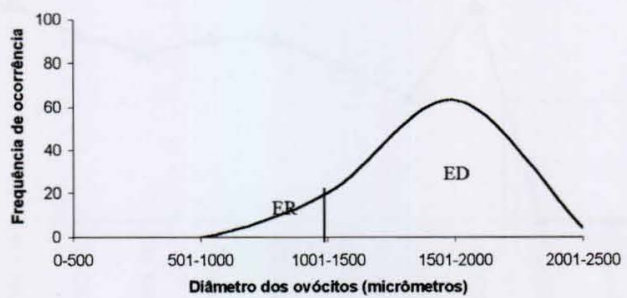

Fig. 5. Freqüências de ocorrência dos ovócitos encontrados em peixes voadores em diversos estádios de maturação gonadal. (ER) Estoque de reserva, (ED) estoque em desenvolvimento.

Tabela I Estádios de maturação gonadal para fêmeas de $H$. affinis.

\begin{tabular}{|c|c|c|}
\hline Estádio & Características macroscópicas & Características microscópicas \\
\hline Imaturo & $\begin{array}{l}\text { Ovários pequenos, filiformes, translúcidos e sem } \\
\text { vascularização }\end{array}$ & $\begin{array}{l}\text { As lamelas ovigeras sāo estreitas e recobertas por } \\
\text { células basófilas, apresenta ovócitos do estoque } \\
\text { de reserva (Fase II) e ninhos de células } \\
\text { germinativas (ovogônias) }\end{array}$ \\
\hline Em maturação I & $\begin{array}{l}\text { Ovários maiores em tamanho ocupando } 1 / 3 \mathrm{da} \\
\text { cavidade celomática e vascularizados }\end{array}$ & $\begin{array}{l}\text { Apresenta ovócitos de estoque de reserva (Fase II) } \\
\text { e alguns ovócitos com vitelogênese lipidica (Fase } \\
\text { III). Ninhos de células germinativas e lamelas } \\
\text { ovigeras bem visiveis. Ovócitos entre } 500-1000 \\
\mu \mathrm{m}\end{array}$ \\
\hline
\end{tabular}

Em maturação II Ovários bem vascularizados com ovócitos visiveis a olho nu

O diâmetro dos ovócitos apresenta-se bem maiores que no estádio anterior (1000-2000 $\mu \mathrm{m})$, apresentando dominância dos ovócitos com vitelogênese lipídica e protéica (Fase IV) e alguns com vitelogênese completa (Fase V)

Maduro Ovários túrgidos ocupando $2 / 3$ da cavidade celomática, com maior números de ovócitos grandes visiveis a olho nu
Maduro inicial - Predominância de ovócitos na Fase $\checkmark$ que está com vitelogênese completa, apresentando membrana vitelina espessa e 0 citoplasma apresenta-se repleto de grânulos de vitelo

Maduro final - Predominância de ovócitos na Fase VI que são os ovócitos em hialinização que estão aptos para serem desovados (2000-2500 $\mu \mathrm{m})$. Os ovócitos apresentam-se bastante irregulares e separados entre si devido a hidratação sofrida pelo citoplasma 
Tabela II Estádios de maturação gonadal para machos de H. affinis.

\begin{tabular}{|c|c|c|}
\hline Estádio & Caracteristicas macroscópicas & Caracteristicas microscópicas \\
\hline Imaturo & $\begin{array}{l}\text { Testiculos de tamanho reduzido e filiformes, } \\
\text { com posição semelhante a dos ovários }\end{array}$ & Túbulos seminíferos de diâmetro reduzido \\
\hline Em maturação & $\begin{array}{l}\text { Testículos mais desenvolvidos e com forma } \\
\text { lobulada }\end{array}$ & $\begin{array}{l}\text { Observam-se túbulos repletos de espermatozóides } \\
\text { além de cistos de células germinativas }\end{array}$ \\
\hline Maduro & $\begin{array}{l}\text { Testículos túrgidos e esbranquiçados, ocupando } \\
\text { grande parte da cavidade abdominal }\end{array}$ & $\begin{array}{l}\text { Apresenta massas compactas de espermatozóides } \\
\text { nos túbulos }\end{array}$ \\
\hline Esvaziado & Testículos flácidos com aspecto hemorrágico & $\begin{array}{l}\text { Há redução no diâmetro dos túbulos apresentando } \\
\text { espermatozóides residuais }\end{array}$ \\
\hline
\end{tabular}

Os valores médios do fator de condição variaram de 0,71 a 1,09 para machos e de 0,69 a 1,07 para fêmeas, durante o período de estudo. As fêmeas e os machos apresentaram valores maiores no mês de abril. $\mathrm{O}$ fator de condição apresentou um padrão de variação semelhante para ambos os sexos (Fig. 6).

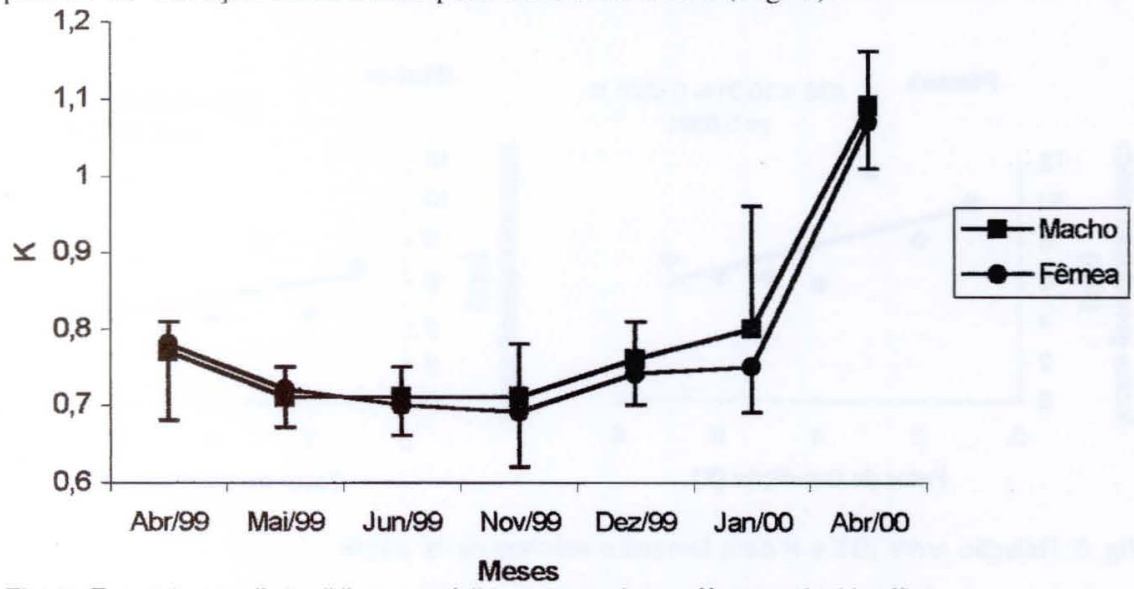

Fig. 6. Fator de condição $(K)$ com média para machos e fêmeas de $H$. affinis.

Os valores médios do IGS variaram de 3,80 a 8,02 para machos e de 5,87 a 11,39 para fêmeas. As fêmeas apresentaram valores maiores no mês de junho acontecendo o mesmo para machos sendo que as fêmeas apresentaram valores maiores que os machos durante o período total de estudo (Fig. 7). Houve uma relação negativa entre o Fator de condição (K) e o Índice gonadossomático (IGS) tanto para fêmeas quanto para machos (Fig. 8).

Observou-se através dos gráficos de regressão entre IGS e peso total $(\mathrm{r}=$ $0,2206 \mathrm{M} ; \mathrm{r}=0,4948 \mathrm{~F})$ e IGS e comprimento total $(\mathrm{r}=0,4483 \mathrm{M} ; \mathrm{r}=0,1195 \mathrm{~F})$ que não ocorre dependência entre as variáveis.

Os resultados da variação do índice gonadossomático apresentando os maiores valores nos meses de abril, maio e junho, juntamente com os valores mínimos do fator de condição no mesmo período, além do elevado número de ovas (gônadas) coletadas pelos pescadores, indicam que a provável época de reprodução de $H$. affinis, acontece entre abril e junho. 


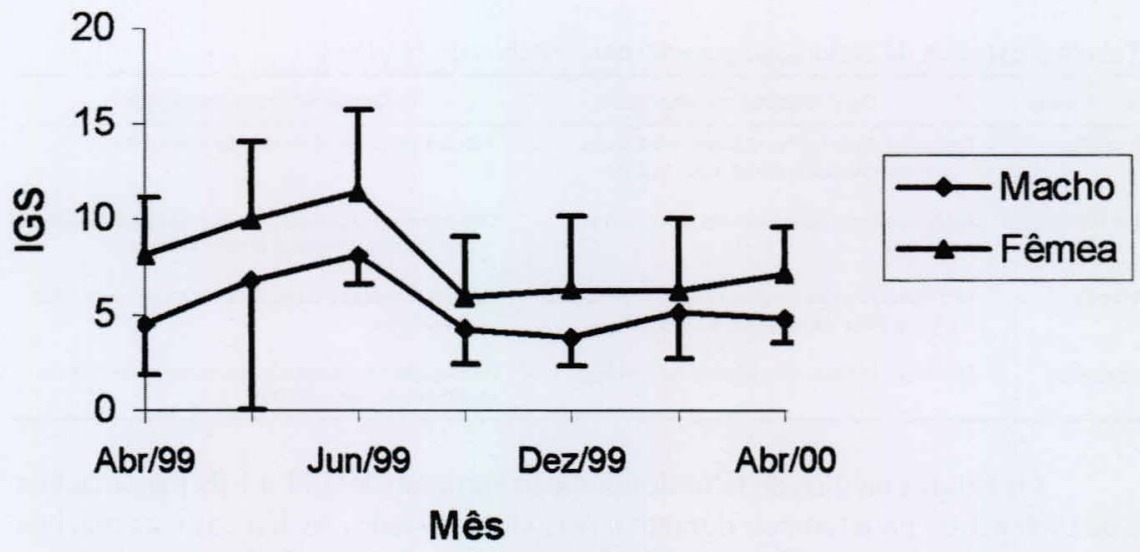

Fig. 7. Índice gonadossomático (IGS) com média para machos e fêmeas de $H$. affinis.
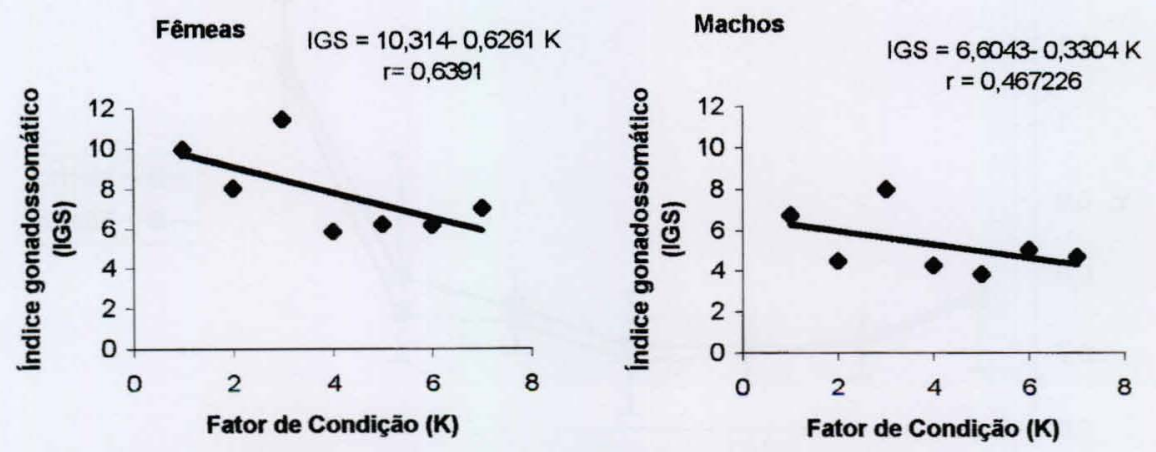

Fig. 8. Relação entre IGS e K para fêmeas e machos de $H$. affinis.

\section{DISCUSSÃO}

O comprimento médio da primeira maturação gonadal é de fundamental importância para a administração racional dos estoques, pois constitui um elemento para fixação dos tamanhos mínimos de captura e para a determinação do tamanho das malhas da rede.

Segundo NiKOLSKY (1963), geralmente a proporção sexual não difere, mas pode sofrer variação em diferentes espécies e até mesmo na mesma população em diferentes períodos, mas que geralmente ela ocorre de 1:1. Esse autor afirma ainda que a proporção entre os sexos é importante na reprodução de uma população e que esta razão sexual varia em espécies de acordo com as diversas faixas etárias e tamanho dos reprodutores. VAZZOLER (1996) considera que a proporção sexual nos peixes varia ao longo do ciclo de vida em função de eventos sucessivos, constituindo-se uma tática reprodutiva, agindo de modo distinto sobre os indivíduos de cada sexo. No presente estudo, a proporção sexual observada para o $H$. affinis foi de 1:1 
com uma leve predominância de fêmeas nos meses de maio e junho. Nossos resultados estão concordando com os trabalhos realizados por BARROS \& MORAIS (1968) que registraram 1033 fêmeas e 747 machos e por CRUZ \& ARAÚJO (1971) 683 machos e 730 fêmeas.

O fator de condição $(\mathrm{K})$ é indicador do grau de bem estar do peixe, refletindo condições alimentares. Alguns autores consideram que para a avaliação do fator de condição deve ser subtraído do peso total do peixe, o peso das gônadas (PAYNE 1975) e o peso do estômago (SIDDIQUi 1977), uma vez que aqueles valores podem alterar os resultados, dando indicações não muito reais do bem estar biológico dos peixes. Nossos resultados mostram que o fator de condição reflete mudanças que ocorrem no peixe. $\mathrm{O}$ fator de condição foi mais alto entre os indivíduos menores, diminuindo gradativamente em peixes maduros. O declínio no fator de condição ocorreu durante a maturação gonadal da espécie. Em geral, há uma transferência das reservas energéticas do peixe, para suprir o desenvolvimento das gônadas (CHELlaPPA et al. 1995). Este fato está em concordância neste trabalho, no qual se verificou uma relação negativa entre o fator de condição e índice gonadossomático (IGS).

Em função da estreita relação entre o avanço do processo de desenvolvimento ovocitário e o aumento do volume e do peso dos ovários, verifica-se um aumento do valor do IGS (VAZZOLER 1996). Os maiores valores de IGS são constatados no momento que antecede a desova, devido à hidratação dos óvulos. Este índice pode ser considerado como um dos indicadores do período de desova. Neste trabalho $H$. affinis apresentou maior IGS durante o período de desova o que seria um resultado esperado, sendo que os valores do IGS das fêmeas foram superiores aos dos machos.

A definição exata dos estádios de maturação gonadal só é válida quando se processam análises macro e microscópica das gônadas. A análise histológica, tanto para machos quanto para fêmeas, confirmou o diagnóstico dos estádios maturacionais determinados macroscopicamente. As características macro e microscópicas dos ovários permitiram estabelecer a escala de maturação para as fêmeas e machos em quatro estádios, ou seja, imaturo (jovem), em maturação, maduro e esgotado.

Histologicamente, os testículos apresentam túbulos seminíferos com cistos espermáticos. Os túbulos são revestidos na fase interna por células císticas (Sertoli) que, por sua vez, envolvem as células espermatogênicas, formando um cisto. As células espermatogênicas de um mesmo cisto encontram-se no mesmo estádio de desenvolvimento. Estes resultados estão de acordo com as descrições feitas por ANDRADE-TALMELLI et al. (1996) em relação à tainha, Mugil platanus.

As características observadas em ovócitos de várias fases são semelhantes às descritas por MONTE (1965). Os ovócitos foram classificados em: ovócitos avitelogênicos (100 $\mu \mathrm{m}$ de diâmetro), ovócitos pré-vitelogênicos $(300 \mu \mathrm{m})$, ovócitos em vitelogênese (entre 500 a $1500 \mu \mathrm{m}$ ), e óvulos maduros (de 1500 a $2500 \mu \mathrm{m}$ ). O mecanismo de desenvolvimento dos ovócitos permite amadurecimento e o pronto esvaziamento dos ovários. 
As estimativas de fecundidade exigem análises quanto à distribuição da frequiência do diâmetro dos ovócitos e os aspectos da histologia dos ovários. Com base nos resultados obtidos com relação a esses aspectos, a fecundidade poderá ser estimada de modo mais consistente do que os outros métodos (VAZZOLER 1996). Os resultados do presente estudo indicam uma fecundidade de 4.400 e 6.400 ovócitos para o peixe voador.

Neste trabalho, o peixe voador apresenta um desenvolvimento ovocitário sincrônico em dois grupos o que indica o tipo de desova total, onde as células ovocitárias existentes nos ovários maturam simultaneamente, sendo eliminados de uma só vez durante o período de desova. Entretanto, CRUZ \& ARAújo (1971) considera o tipo de desova apresentado pelo peixe voador como desova parcelada, diferindo dos nossos resultados.

Um outro fator a ser considerado quanto ao tipo de desova é o IGS, onde peixes com desova parcelada apresentam baixo IGS em relação ao desenvolvimento dos ovócitos em lotes que são liberados em intervalos. Enquanto os peixes com desova total tem IGS alto (WILK et al. 1990), como no caso do peixe voador. (JONS \& MIRANDA 1997) relatam que a relação entre o peso dos ovários, tamanho dos ovócitos e fecundidade varia muito em espécies diferentes dos peixes. Portanto, o peso dos ovários não é índice adequado para representar o tipo de desova.

MONTE (1965) observou que o desenvolvimento das células reprodutoras resulta no pronto esvaziamento do ovário em peixes voadores, $H$. affinis nas águas do litoral em frente a Caiçara do Norte, e portanto nossos resultados estão de acordo com as observações descritas por este autor. Ele também observou que as fêmeas desovam na superfície das águas em pequenos grupos.

Os peixes reproduzem-se na época do ano em que as condições ambientais são favoráveis à maximização da produção de descendentes durante seu ciclo reprodutivo (WoOTTON 1990). Sendo assim, suas pós-larvas terão alimento apropriado, proteção contra predadores e condições extrínsecas (abióticas) favoráveis.

Hirundichthys affinis, sendo epipelágico, habita águas superficiais do Oceano Atlântico do Nordeste Brasileiro, onde a temperatura de $26^{\circ} \mathrm{C}$ e salinidade de $36,2 \%$ o se mantêm relativamente constantes (CRUZ \& ARAÚJo 1971). A ocorrência do peixe voador na região oceânica próximo ao município de Caiçara do Norte ocorre logo após a estação chuvosa de março a junho. A precipitação pluviométrica é considerada fator climático importante para desencadear o final do processo de maturação das gônadas e a desova. A desova do peixe voador ocorre entre os meses de maio a junho quando foram registrados os maiores valores do índice gonadossomático dos peixes coincidindo também com o período de chuva.

Considerando-se que tanto o índice gonadossomático (IGS) como o fator de condição $(\mathrm{K})$ refletem o grau de maturidade dos peixes podemos ratificar através desses índices que o provável período de reprodução estende-se de abril a junho.

\section{CONCLUSÕES}

Os estudos realizados para determinar a estratégia reprodutiva de $H$. affinis no Município de Caiçara do Norte, permitiram chegar às seguintes conclusões. 
Hirundichthys affinis apresenta várias táticas reprodutivas, tais como: tamanho da primeira maturação gonadal distribuído por intervalos de classes de comprimento total determinado pelo L50, indica que os machos apresentaram um L50 de $238 \mathrm{~mm}$ e as fêmeas $230 \mathrm{~mm}$. A proporção sexual é de 1:1, com uma leve predominância de fêmeas nos meses de maio e junho. O fator de condição é inversamente proporcional ao IGS. O maior índice gonadossomático de ambos os sexos corresponde com a época de reprodução. As fêmeas e os machos apresentam quatro estádios de desenvolvimento gonadal: imaturo, em maturação, maduro e esvaziado. Os aspectos histológicos das gônadas sugerem que o amadurecimento e ovulação se processa em curto espaço de tempo. A fecundidade varia entre 4.400 ovócitos e 6.400 ovócitos maduros, com uma média de 5.400. O período de desova ocorre nos meses de maio e junho que coincide com o período de chuvas. A desova é do tipo total liberando todos os ovócitos maduros de uma só vez. Os óvulos liberados apresentam-se com tamanho entre 2000 a $2500 \mu \mathrm{m}$ em diâmetro. A ocorrência do peixe voador na fase reprodutiva, na área oceânica do litoral norte do Rio Grande do Norte foi observada logo após a estação chuvosa.

\section{REFERÊNCIAS BIBLIOGRÁFICAS}

ALmEIDA, N.U. 1966. Estudos sobre a maturidade do peixe voador (Hirundichthys affinis Günther, 1866) na costa nordestina do Brasil. Bol. Est. Pesca, Recife, 6 (3): 33-41.

Andrade-Talmelli, E.F.; E. Romagosa.; M.Y. Narahara \& H.M. Godinho. 1996. Características reprodutivas de tainha, Mugil platanus (Teleostei, Perciformes, Mugilidae) da região Estuarino-lagunar de Cananéia, Revta Ceres, São Paulo, 43 (246): 165-185.

Barros, A.C. \& S.B Morais. 1968. Prospecção de áreas de pesca de peixe-voador (Cypselurus cyanopterus Valenciennes, 1846) ao longo do litoral dos Estados de Pernambuco e Paraíba. Bol. Est. Pesca, Recife, 8 (3): 9-16.

Chellappa, S., F.A. Huntingford; H.C. Strang \& R.Y Thomson. 1995. Condition factor and hepatosomatic index as estimates of energy status in male three-spined sticlclebarck. Jour. Fish Biol. 47: 775-787.

CRUZ, J.F. 1965. Sobre a biologia pesqueira do voador Hirundichthys affinis (Gunther 1866), no Nordeste do Brasil. Bol. Inst. Biol. Mar., Natal, 2: 19-31.

CRUZ, J.F. \& M.S. ARAúJo. 1971. Notas sobre alimentação de Hirundichthys affinis (Gunther 1866), ao largo do Nordeste brasileiro. Bol. Inst. Biol. Mar., Natal, 5: 31-37.

Jons, A.D. \& L.E. MirandA. 1997. Ovarian weight as an index of fecundity, maturity and spawning periodicity. Jour. Fish Biol. 50: 150-156.

LE CREN, E.D. 1951. The length-weight relatioship and seasonal cycle in gonad weight and condition in the perch (Perca fluviatilis). Jour. Animal Ecol., London, 20: 201-219.

MichalanY, J. 1990. Técnica histológica em anatomia patológica com instruções para o Cirurgião, Enfermeira e Citotécnico. São Paulo, $2^{\mathrm{a}}$ ed., 247p.

Monte, S. 1965. Contribuição ao estudo da reprodução de "voador" Hirundichthys affinis (Gunther 1866). 1965. Bol. Inst. Biol. Mar., Natal, 2: 1-18.

Nikolsky, G.V. 1963. The Ecology of fishes. London, Academic Press, 352p.

PIRES, I. 1997. De isca a caviar: potencial econômico dos peixes-voadores do nordeste ainda é pouco explorado. Ciência Hoje 22: 67-68.

PAYNE, A.I. 1975. The reproductive cycle, condiction and feeding in Barbus liberiensis, a tropical cypnnid. Jour. Zool. Lond. 176: 247-269.

PotTs, G.W. \& R.J. Wootton. 1984. Fish reproduction: strategies and tactics. London, Academic Press, 410p.

SidDiQui, A.Q. 1977. Reproductive biology, length-weight relationship and relative condtion of Tilapia

Revta bras. Zool. 19 (3): 691 - 703, 2002 
leucosticta. Jour. Fish Biol. 10 (3): 251-260.

Simpson, A.C.1951. The fecundity of the Plaice. Fish. Invest., London, 17 (5): 1-27.

VAZzoLER, A.E.A.M. 1996. Biologia de reprodução de peixes Teleósteos: teoria e prática. Maringá, EDUEM, 169p.

WiLK, S.J.; W.W.MORSE \& L.L. STEHLIK. 1990. Annual cycles of gonadosomatic indices as indicators of spawning activity for selected species of flying fish colleted from the New York Bight. Fishery Bull. 88: 775-786.

Wootton, R.J. 1984. Introduction: Strategies and tactics in fish reproduction, p. 1-12. In: G.W. PотTS \& R.J. WootTon (Eds). Fish reproduction: strategies and tactics. London, Academic Press, 410p. 1990. Ecology of teleost fishes. London, Chapman \& Hall, 404p.

Wootron, R.J.; G. W evans \& L. Mills. 1978. Annual cycle in female three-spined sticklebacks

(Gasterosteus aculeatus L) from an upland and lowland population. Jour. Fish Biol. 12: 331-343.

Recebido em 25.V.2001; aceito em 19.VII.2002. 